\title{
A transactional approach to predicting stress experienced when writing dissertations
}

\section{Fortunate Tintswalo Silinda}

\begin{abstract}
Although substantial attention has been given to doctoral students, the attention given to master's students writing dissertations is limited. This article outlines a transactional model of stress that conceptualises dissertation writing as a stressor consisting of a series of phases that tend to increase the risk of negative outcomes. A mixed-method design was used to address the aim of the study. An adapted version of the Stress and Support Questionnaire for University Students was used to measure the stress that master's students experienced. Open-ended questions were employed to measure students' evaluations of the stress experienced when writing a dissertation. The model proposed that the phases of dissertation writing moderate the relationship between stressor factors and the stress experienced. In an empirical study making use of the model, the moderation analyses revealed that Phase I of dissertation writing significantly moderated the relationship between the stress experienced, stressor factors of relationships, financial and transport problems and health related problems. The qualitative data suggested that stress is evaluated either positively or negatively depending on time-management styles and support systems. The results obtained underscore the importance of support structures in alleviating the stress experienced when writing dissertations in order to improve students' retention and graduation rates.
\end{abstract}

\section{Keywords}

Coping, dissertation, master's, stress, stressor, student

\section{Introduction}

The level of study at which a dissertation is executed varies among countries. In South Africa, the concept refers to a research project that a student submits towards obtaining a master's degree,

University of South Africa, South Africa

Corresponding author:

Fortunate Tintswalo Silinda, Department of Psychology, School of Social Sciences, University South Africa, Pretoria, P O Box 392, UNISA, Pretoria 0003, South Africa.

Email: silinft@unisa.ac.za 
while in the United States, it refers to a research project that is submitted towards completion of a doctoral degree. In this article, the concept is used to describe the research project of a master's student that is submitted towards a master's degree. The goal of every student who enrols for a degree is to gain the qualification. However, master's students encounter stressful challenges, which, if not adequately dealt with, may force them to abandon their studies. Student attrition has been linked to a number of demographic factors (e.g., age, ethnicity, and gender) and social factors (e.g., finances, family responsibilities, and employment). In addition, certain psychological factors have been linked to postgraduate student attrition and include lack of academic and social adjustment (Gardner, 2009; Lovitts, 2001), perceived lack of support from the academy (university and academic departments), lack of support from employers and/or family members (El-Ghoroury, Galper, Sawaqdeh, \& Bufka, 2012; Gardner, 2009; Overall, Deane, \& Peterson, 2011), procrastination (Flett, Stainton, Hewitt, Sherry, \& Lay, 2012; Jiao, DaRos-Voseles, Collins, \& Onwuegbuzie, 2011), and fear of failing (Overall et al., 2011). Moreover, financial problems, lack of balance between studies and work, and family commitments (Herman, 2011; Taylor \& Owusu-Banahene, 2010) have also been linked to student attrition.

\section{Transactional Model of Stress in Education}

A useful framework for understanding the potential predictive nature of master's students' perceptions regarding a stressor is the transactional model of stress by Lazarus and Folkman (1984). The transactional approach views stress as a process that involves continuous interactions and adjustments known as transactions between an individual and the environment. The individual is regarded as an active agent who can influence the impact of a stressor through behavioural, cognitive, and emotional strategies.

For the purpose of this study, the transactional model of stress was found to be the most satisfactory theoretical framework to emphasise the relationships between persons and their environment. According to Lazarus and Folkman (1984), stress is a particular relationship between an individual and the environment appraised by the individual as taxing or exceeding available coping resources and posing a threat to their well-being. This suggests that stress for a student denotes a relationship between the student and the learning environment that poses significant challenges (e.g., the various phases of dissertation writing) in developing coping mechanisms to deal with this stress effectively.

The transactional model consists of a central feature concerning stress, which is a cognitive process (Lazarus, 1966). It comprises the assessment of an individual regarding whether a demand threatens his or her well-being and an appraisal of the resources required for meeting the demand. Two processes are involved. The primary appraisal is informed by the individual's initial perception of whether an event or stressor is irrelevant, benign-positive, or stressful. Events perceived as stressful are further appraised as challenges or hindrances. Events perceived as having the potential for growth are referred to as challenge appraisals, while those events perceived as harmful to the attainment of goals are referred to as hindrance appraisals (Lazarus \& Folkman, 1984; Webster, Beehr, \& Love, 2011). Master's students may appraise stress as both a challenge and a hindrance (Lazarus \& Folkman, 1984; Webster et al., 2011). For example, writing a dissertation has the potential of bringing joy to the student because the student will be completing the programme upon successful submission of the dissertation. However, students are also at risk of experiencing stress if they find it difficult to cope with the multiple responsibilities (i.e., study, work, and family responsibilities).

The secondary appraisal follows the primary appraisal process. It involves an individual's coping responses that consist of attempts to engage and change the perceived stress (Folkman, 1997). 
Lazarus and Folkman (1984) defined effective problem-solving as efforts made by an individual when the demands of a given situation tax adaptive resources. Therefore, coping is an individual's assessment of the specific actions and behaviours that should be undertaken in a stressful event. According to Shapiro (1983), coping resources are

[A]spects of the individual's external and internal environment, which are either not directly or completely under the individual's control; they exist in a quiescent state ready to mediate in a positive or negative direction the individuals' [sic] response to the advent of a stressor. The nature and type of coping resources is determined by prior knowledge, experience, educational attainment, and socioeconomic status. (p. 915)

Coping strategies are actions that an individual takes in a specific situation with the intention of reducing stress, for example, asking for help. When an individual is unable to cope, it means that the demands exceed the resources.

The justification for the challenge-hindrance postgraduate stress model's framework rests on the transactional theory of stress. However, research on the theory in educational settings has only assumed psychological and environmental factors contribute to the experience of stress (D'Zurilla \& Sheedy, 1991; Gibbons, 2010; LePine, LePine, \& Jackson, 2004). However, there are moderators interacting between the appraisal of stress and an individual's response. These moderators include the phase a student is engaged in when writing dissertations. Although there has been an abundant amount of research demonstrating the role of psychosocial and environmental stressors as determinants of strains, research on the primary appraisals as one of the key intervening mechanisms in the stress experienced by master's students is limited. This is one of the few studies in which these different stressors and moderators were considered.

\section{Stressors Experienced When Writing Dissertations}

There is extensive research on possible stressors that can be encountered by doctoral students who have the potential to affect academic persistence negatively (Gardner, 2009; Golde, 2005; Herman, 2011; Lovitts, 2001; Martinsuo \& Turkulainen, 2011; Overall et al., 2011). For example, international studies show that at least $40 \%$ of doctoral students leave university without completing their studies (Golde, 2005). While there is a scarcity of literature concerning the graduation and attrition rates of master's students internationally, in South Africa it is estimated that approximately $32 \%$ of the students enrolled for master's and doctoral programmes abandon their studies (Department of Higher Education and Training, 2013). It is important that the challenges encountered by master's students are identified so that the same challenges are not encountered when the students proceed with their doctoral studies.

Studies conducted among doctoral students demonstrate that the difficulties students encounter in balancing their multiple roles often have the potential to affect their health and well-being (Martinez, Ordu, Della Sala, \& McFarlane, 2013; Maunganidze, Sodi, Mudhovozi, Mberi, \& Mutasa, 2010). Procrastination is another stressor that has an impact on students' well-being (Flett et al., 2012). For instance, students may decide to delay collecting data or writing a particular chapter of their dissertations, and this may lead to students experiencing stress when they resume their research activities because they are uncertain of where to start. Jiao et al. (2011) found that postgraduate students who experienced poor academic persistence were those who tended to procrastinate performing administrative tasks, keeping abreast with weekly reading assignments, and writing term papers. Delaying research activities may lead students to experience stress, particularly when they do not have a strong support structure in place. Lovitts (2001) argues that social structures promote student retention and contribute towards a better adjustment to the postgraduate programme. 
Students who experience a lack of support have also been reported to be prone to stress (Gardner, 2009; Overall et al., 2011). In such situations, students are more likely to experience stress and low levels of research self-efficacy, which may force them to abandon their studies (Lovitts, 2001). Support from peers and the faculty is imperative for students' development during their postgraduate journey because support helps students to adjust to the academic demands of their programme. Martinsuo and Turkulainen (2011) found that goal commitment and support from friends, members of the family, and supervisors have a positive effect on research progress (students' ability to access relevant knowledge, to solve problems, and to spend time on the dissertation).

There are a limited number of studies that focus on the dissertation writing process of master's students leading to the experience of stress, and these studies tend to concentrate on the structure of a master's dissertation (Paltridge, 2002; Samraj, 2008). Samraj (2008) argues that master's dissertations do not constitute a homogeneous set of texts due to the different disciplines and their requirements. Other studies focus on the cultural and language barriers that international students encounter when writing dissertations (Cadman, 1997; Li \& Vandermensbrugghe, 2011; Wang \& $\mathrm{Li}, 2008$ ). However, these studies do not examine the stress experienced by students when writing dissertations. Therefore, this study sought to answer the following research questions: What are the implications of the phases of dissertation writing for stressors and the stress experienced? What are students' evaluations of the stress experienced when writing a dissertation?

A convergent parallel design (Creswell, 2013) was used to address the above-mentioned research questions. This mixed-method design was used to collect both quantitative and qualitative data concurrently. The design was also employed for triangulation because the quantitative results were compared and contrasted for corroboration and validation purposes. The method was useful for capturing a holistic and contextual portrayal of stress.

The aim of this study was to extend the transactional model of stress by examining the stress experienced. According to the theoretical framework reviewed, it was assumed that stressors moderate the relationship between the phases of dissertation writing and the stress experienced, and that the stress experienced is evaluated as either a positive or negative stress.

\section{Method}

\section{Participants}

The sample consisted of 528 master's students who were writing dissertations at a distancelearning university. A response rate of $10 \%$ was achieved. Although the response rate was low, it was consistent with the survey response rates reported by Porter and Umbach (2006) who highlighted that survey response rates were declining. However, Chaudron (2006) emphasised that a survey has proved to be a reliable data collection method. It was determined that the low response rate for this study was due to the contact information provided by the university being out of date.

The participants consisted of $(n=223,42.2 \%)$ females and $(n=305,57.8 \%)$ males. The gender distribution of the study reflects gender imbalances between males and females in South Africa (Brand South Africa, 2017). The mean age was 37.4 years (standard deviation $[S D]=8.0$ years, range: $23-71$ years). In terms of racial representation, ${ }^{1}$ the majority of the participants were Black African $(n=399,75.6 \%)$, and the remaining participants were White $(n=100,18.9 \%)$, Indian/ Asian $(n=23,4.4 \%)$, and Coloured $(n=6,1.1 \%)$. The average number of years enrolled for postgraduate studies was 1.9 years $(S D=2.0$ years, range: $0-15$ years). The sample distribution by faculty was Faculty of Human Sciences $(n=178,33.7 \%)$; Faculty of Economic and Management Sciences $(n=129,24.4 \%)$; College of Law $(n=108,20.5 \%)$; Faculty of Science, Engineering and 
Technology $(n=51,97 \%)$; Faculty of Agriculture and Environmental Sciences $(n=41,7.8 \%)$; and Faculty of Accounting Sciences $(n=21,4.0 \%)$.

\section{Instruments}

The present study used a cross-sectional survey to assess the dependent and independent variables. Stress experienced was the dependent variable, while stressors and dissertation writing were the independent variables.

Stress experienced was measured using the following item: 'To what extent do you experience stress-related symptoms in the dissertation/thesis writing phase you are in currently?' Participants responded to this item on a 5-point scale that ranged from $1=$ not at all to $5=$ to a large extent .

Stressors were measured using an adapted version of the Stress and Support Questionnaire for University Students (SASQUS) developed by Pillay and Ngcobo (2010). Students were asked to indicate the intensity of stress that they experienced regarding the stressor items.

Although the SASQUS was originally developed for undergraduate students, the measure has several subscales that were relevant for the study. Several items were adapted to suit the context of master's students to make it suitable for the target group. An example of the added items included supervisors not supportive, pushing oneself beyond the limit, procrastination, and failing to meet deadlines. The original scale comprised a dichotomous scale, whereas a Likert-type scale of $1=n o$ stress to $5=$ extreme stress was used in the adapted scale. Students were asked to indicate the intensity of the stress they experienced while engaged in the phases of dissertation writing. Two stress and supervision experts as well as two postgraduate alumni who have written dissertations were consulted to verify the items before the questionnaire was administered. The adapted scale consisted of 24 items with a reliability coefficient of .92 and measured the stressors that students experienced when writing dissertations. The adapted SASQUS scale consisted of the following five stressor subscales: relationship stressors $(\alpha=.89)$, time-management stressors $(r=.49, n=528$, $p<.001)$, academic stressors $(\alpha=.67)$, health stressors $(\alpha=.87)$, and financial and transport problems $(\alpha=.87)$.

Dissertation writing was measured using 14 items with a reliability coefficient of .73 to indicate the various phases of dissertation writing. Participants were asked to indicate whether they were engaged in the listed phases of dissertation writing on a dichotomous scale (yes or no). Participants who were not writing dissertations were not included in the analysis.

The 14 dissertation writing items together constituted an extensive list of the various dissertation writing phases. A factor analysis was conducted to determine whether the 14 phases could be combined into a smaller set of distinct phases since students may be in certain phases simultaneously. An exploratory factor analysis was used to combine the phases of dissertation writing by calculating the mean score of these items. This reduced the 14 dissertation writing items into a set of four dissertation writing factors based on the eigenvalue of $>1$ criterion. The factors accounted for $55 \%$ of variance. Table 1 illustrates the factor loadings after direct oblimin rotation. Individual items with greater or equal to .40 factor loadings that were loaded on a single factor were retained. The four phases ${ }^{2}$ were as follows: (1) Phase 1 - the submission of the chapter(s) regarding interpretation and limitations, the submission of the chapter(s) regarding the research findings, the submission of the analysis chapter(s), and the final editing of the dissertation draft $(\alpha=.62)$; (2) Phase 2 - the writing of the introduction, theoretical framework, literature review, and research methodology $(\alpha=.63)$; (3) Phase 3 - the submission of the research methodology chapter(s) and the submission of the theoretical framework and literature review chapter(s) $(\alpha=.62)$; and (4) Phase 4 - the writing of the analysis chapter(s) and the writing of the chapter(s) regarding the research findings $(\alpha=.64)$. These phases are distinct in the following ways: Phase 1 is mainly on 
Table I. Descriptive statistics of stressors and stress.

\begin{tabular}{|c|c|c|c|c|c|c|c|c|c|c|c|}
\hline Variable & $M(S D)$ & I & 2 & 3 & 4 & 5 & 6 & 7 & 8 & 9 & 10 \\
\hline Stress & $3.50(1.20)$ & - & & & & & & & & & \\
\hline $\begin{array}{l}\text { Relationship } \\
\text { stressors }\end{array}$ & $1.96(.83)$ & $.073^{*}$ & - & & & & & & & & \\
\hline $\begin{array}{l}\text { Academic stressors } \\
\text { and personal } \\
\text { problems }\end{array}$ & $2.58(1.03)$ & $.283 * *$ & $.444 * *$ & - & & & & & & & \\
\hline $\begin{array}{l}\text { Time-management } \\
\text { stressors }\end{array}$ & $2.58(1.02)$ & $.258 * *$ & $.221^{* *}$ & $.376 * *$ & $=-$ & & & & & & \\
\hline Health problems & $2.22(1.03)$ & $.086 *$ & $.654 * *$ & $.496 * *$ & $.223 * *$ & - & & & & & \\
\hline $\begin{array}{l}\text { Financial and } \\
\text { transport problems }\end{array}$ & $2.27(1.07)$ & .066 & $.573 * *$ & $.444 * *$ & $.183 * *$ & $.543 * *$ & - & & & & \\
\hline Phase I & $0.03(0.10)$ & .026 & .047 & .006 & -.021 & .009 & -.016 & - & & & \\
\hline Phase 2 & $0.11(0.24)$ & $.079 *$ & -.019 & -.030 & .024 & -.008 & -.008 & $.107^{* *}$ & - & & \\
\hline Phase 3 & $0.6(0.19)$ & .013 & .042 & -.049 & .021 & .041 & .007 & .009 & $.245^{* *}$ & - & \\
\hline Phase 4 & $0.6(0.19)$ & -.020 & -.012 & -.049 & -.036 & -.049 & -.013 & .067 & $.627^{* * *}$ & $.201 * *$ & - \\
\hline
\end{tabular}

SD: standard deviation.

Note. ${ }^{\dagger}<.10 ; *_{p}<.05 ; * * p<.01 ; * * * p<.001$

the submission of chapters in the final stages of the dissertation; Phase 2 is related to the writing process of the first three dissertation chapters; Phase 3 is related to the submission of the literature review and research methods; and Phase 4 is in line with writing chapters in the final stages of the dissertation.

Qualitative data were derived from open-ended questions in the online survey. This provided additional means for exploring students' appraisal of the sources of stress they might experience during the process of writing a dissertation. Participants were asked to write down their evaluations of the stress experienced when writing a dissertation and to indicate their attributions of the stress they experienced while writing dissertations.

\section{Procedure}

Data were collected in the form of a cross-sectional survey using the Internet platform LimeSurvey. Participants were informed that the study aims to investigate postgraduate students' experiences when writing dissertations. They were also informed that their responses would be treated confidentially.

\section{Ethical Consideration}

Ethical clearance to conduct this study was granted by the Department of Psychology and the Senate Research and Innovation and Higher Degrees Committee at University of South Africa (UNISA). The University granted approval to use data obtained from students enrolled for master's programmes. Students' participation in this study was voluntary and their anonymity was guaranteed. No incentives were provided to participants.

\section{Data Analysis}

Moderation analyses were conducted with stress experienced as the outcome variable to determine the impact of various phases of dissertation writing on the relationship between stressors and the 
stress experienced. Qualitative data were also collected to understand students' evaluation of the stress experienced when writing dissertations. Thematic analysis associated with Strauss and Corbin's (1998) constant comparison method and open, axial, and selected coding for qualitative data were used. Two independent researchers verified the identified themes by presenting and supporting their decisions regarding selected themes.

\section{Results}

\section{Descriptive Analysis}

Descriptive statistics and bivariate correlations for all variables are provided in Table 1. Stress experienced significantly positively correlated with the stressor factors of relationship, academics, time management, and health problems. In addition, stress experienced significantly positively correlated with Phase 2 of dissertation writing (the writing of the introduction, theoretical framework, literature review, and research methodology). Phase 2 of dissertation writing significantly positively correlated with Phase 1 (the submission of the interpretation, research findings and analysis chapters, and the editing of the draft dissertation), Phase 3 (the submission of the research methodology, theoretical framework, and literature review chapters), and Phase 4 (the writing of the chapters regarding the analyses and the research findings). Phase 3 also significantly positively correlated with Phase 4. These findings confirm the assumption that dissertation writing phases contribute to stress experienced by postgraduate students.

\section{Preliminary Analysis}

An analysis of variance (ANOVA) was conducted to test the differences between stress experienced, gender, and faculty. There were significant statistical differences between stress experienced and gender, $F(1,526)=31.01, p=.01$. There were, however, no significant statistical differences between stress experienced and faculty. Therefore, gender differences were controlled in the moderation analysis.

\section{Moderation Analysis}

Moderation analyses were performed to examine the interactive effects of stressors and the phases of dissertation writing in predicting the stress experienced after controlling for the effects of gender. A simple moderation model was tested using the PROCESS software developed by Hayes and Preacher (2014). Stress experienced was entered as an outcome variable in the first model, relationship stressors as the independent variable, Dissertation Writing Phase 1 as the moderator variable, and gender as a covariate. The results revealed that the model testing whether dissertation writing moderates the relationship between relationship stressors and stress experienced was significant: $R^{2}=.0099, F(1,523)=9.661, p<.01$ (see Table 2).

In the second model, stress experienced was entered as a dependent variable, financial and transport problems as the independent variable, Dissertation Writing Phase 1 as the moderator variable, and gender as a covariate. Again, the results revealed that the moderation model was significant: $R^{2}=.0107, F(1,523)=11.013, p>.01$. The results suggest that dissertation writing moderates the relationship between stressor factors and stress experienced.

In the third model, stress experienced was entered as a dependent variable, health-related stressors as the independent variable, Dissertation Writing Phase 1 as the moderator variable, and gender as a covariate. Again, the results revealed that the moderation was significant: $R^{2}=.0057, F(1$, $523)=4.557, p>.05$. Overall, the tested models predicted more variance in financial and transport 
Table 2. Regression coefficients for effects on stressors.

\begin{tabular}{lllll}
\hline & $B$ & $S E$ & $t$ & $P$ \\
\hline Model I & & & & \\
$\quad$ Constant & 3.2905 & .1561 & 21.0741 & .000 \\
Phase I & -0.1658 & .3702 & -0.4477 & .6545 \\
Relationship stressors & -0.0925 & .0628 & -1.4732 & .1413 \\
Phase I $\times$ Relationship Stressors & -1.9239 & .6190 & -3.1083 & .0020 \\
Gender & -0.5557 & .1032 & -5.3829 & .000 \\
\hline
\end{tabular}

Conditional effects of Phase I at different levels of relationship stressors (indirect measure)

\begin{tabular}{lllll}
\hline Phase I & $B$ & $S E$ & $95 \% \mathrm{Cl}$ \\
\hline At I SD below the mean & -0.0579 & .0642 & {$[-.1840, .068 I]$} \\
At mean & -0.0925 & .0628 & $\begin{array}{l}{[-.2159, .0309]} \\
{[-.4295,-.1043]}\end{array}$ \\
At I SD above the mean & -0.2669 & .0828 & & $p$ \\
\hline & $B$ & $S E$ & $t$ & \\
\hline Model 2 & & & & .000 \\
$\quad$ Constant & 3.2825 & .1564 & 20.9868 & .3905 \\
Phase I & -0.4613 & .5368 & -0.8595 & .0502 \\
Health problems & -0.0947 & .0482 & -1.9629 & .0332 \\
Phase I $\times$ Health Problems & -1.1036 & .5170 & -2.1193 & .000 \\
$\quad$ Gender & -0.5507 & .1032 & -5.3340 & \\
\hline
\end{tabular}

Conditional effects of Phase I at different levels of health problems (indirect measure)

\begin{tabular}{|c|c|c|c|c|}
\hline Phase I & B & SE & \multicolumn{2}{|l|}{$95 \% \mathrm{Cl}$} \\
\hline At I SD below the mean & -0.0748 & .0497 & \multicolumn{2}{|c|}{$[-.1724, .0028]$} \\
\hline At mean & -0.0947 & .0482 & \multicolumn{2}{|c|}{$[-.1894, .0001]$} \\
\hline At I SD above the mean & -0.1947 & .0652 & \multicolumn{2}{|c|}{$[-.3227,-.0667]$} \\
\hline & B & SE & $t$ & $p$ \\
\hline \multicolumn{5}{|l|}{ Model 3} \\
\hline Constant & 3.3220 & .1554 & 21.3765 & .000 \\
\hline Phase I & -0.5689 & .3908 & -1.4555 & .1461 \\
\hline Financial problems & -0.0503 & .0475 & -1.0580 & .2906 \\
\hline Phase I $\times$ Health Problems & -1.7447 & .5257 & -3.3186 & .0010 \\
\hline Gender & -0.5810 & .1026 & -5.6650 & .000 \\
\hline \multicolumn{5}{|c|}{ Conditional effects of Phase I at different levels of financial problems (indirect measure) } \\
\hline Phase I & B & SE & \multicolumn{2}{|l|}{$95 \% \mathrm{Cl}$} \\
\hline At I SD below the mean & -0.0189 & .0488 & \multicolumn{2}{|c|}{$[-.1147, .0769]$} \\
\hline At mean & -0.0503 & .0475 & \multicolumn{2}{|c|}{$[-.1436, .0431]$} \\
\hline At ISD above the mean & -0.2084 & .0661 & \multicolumn{2}{|c|}{$[-.3282,-.0786]$} \\
\hline
\end{tabular}

SE: standard error; Cl: confidence interval; SD: standard deviation.

problems $(11 \%)$ than relationship stressors $(1 \%)$ and health-related stressors $(1 \%)$. Although the moderating effect was significant for the outcome variable, dissertation writing provided a stronger 
moderating effect for financial and transport problems than for relationship stressors and healthrelated stressors.

\section{Thematic Analysis}

Thematic analysis of the open-ended questions suggested two main themes, namely, positive stress and negative stress. Students evaluated the stress experienced while writing dissertations in a positive way and a negative way. The students' narratives provided the study with the students' subjective meanings to the stress experienced when writing dissertations (Delamont, 1992).

\section{Positive Stress}

Students who evaluated stress in a positive way attributed this to being accustomed to working under pressure, good time-management skills, and support from supervisors, colleagues at work, friends, and family members. Mikateko ${ }^{3}$ wrote, 'I am used to working under pressure - somehow, I thrive during that period'.

Another student attributed the positive stress experienced to the support received from supervisors, colleagues at work, friends, and family members. As a result, the stress experienced was motivation for him to work on the dissertation. Risuna wrote, 'Working full-time and having to work on my Dissertation is not easy. But having e-resources from library is a big plus for us and the support from my promoter is enormous'.

Another student, Akani, stated that

[T] he support from the lecturer in guiding us and also through the weekly presentation helps in the process and that takes off a lot of stress as one always knows how to tackle the next chapter. The lecturer is readily available and provides feedback in time which also helps a lot. The library is a great source of resources that I need for my dissertation. Finally, the support and encouragement of my fiancé is quite valuable and keeps me hopeful and going.

The ability to work under pressure and the support from supervisors, colleagues at work, friends, and family members emerged as positive stressors from the analysis. These findings are in line with previous research, which highlights that stress can be evaluated as a challenge and a hindrance (Lazarus \& Folkman, 1984; Webster et al., 2011), and that support is an essential buffer for stress (El-Ghoroury et al., 2012; Lovitts, 2001; Martinsuo \& Turkulainen, 2011).

\section{Negative Stress}

The students who evaluated stress negatively attributed this to lack of feedback, lack of time management, and lack of support from supervisors, colleagues at work, friends, and family members. According to students, the pressures of managing their time contributed to the stress experienced.

Quinton stated,

The time period given to complete the thesis is short if you take into account that some students like myself work full time. Also, the deadlines given by administration and by your study leader differ so it is not clear when what should be completed or submitted and that is very stressful.

Another student, Mike, wrote that 'self-teaching is just strenuous. One needs to actively hunt for information, and it needs time and effort. With limited time plus pressure of other duties, it ends up causing some bit of stress'. 
Research has demonstrated that the lack of support results in increased levels of stress (El-Ghoroury et al., 2012; Gardner, 2009; Lovitts, 2001; Martinsuo \& Turkulainen, 2011). Students also attributed the stress experienced to loss of motivation when writing dissertations. Mmabatho said, 'I wait for too long for feedback, therefore, I worry so much and this overworks me mentally. Anxiety is too much since I am not completing in time'.

\section{Discussion}

Experiencing stress among postgraduate students has been studied extensively in recent years. However, research on the stress experienced while writing dissertations and its consequences on academic persistence is limited (Silinda \& Brubacher, 2016). The main purpose of the present study was to gain a better understanding of one of the theoretical foundations underlying stress, the transactional theory of stress (Lazarus \& Folkman, 1984). A mixed-method research design was used to test the impact of dissertation writing on stressor factors and the stress experienced. The findings in the moderation analyses revealed that the relationship between stressors and the stress experienced is conditional on whether the student is currently engaged in dissertation writing (i.e., the submission of chapter[s] regarding interpretation and limitation, the submission of the chapter(s) regarding the research findings, the submission of the analysis chapter(s), and the final editing of the dissertation draft). The findings of this study complement the research that demonstrates that academic workload leads to the experience of stress (Jacobs \& Dodd, 2003; Klassen \& Chiu, 2010; Mudhovozi, 2011).

The results of the present study also complement findings that demonstrate the link between the stress experienced and relationship problems, health-related stressors, and financial and transport problems (El-Ghoroury et al., 2012; Gardner, 2009; Herman, 2011; Overall et al., 2011; Taylor \& Owusu-Banahene, 2010). These findings can be explained in the context of postgraduate programmes in South Africa (Hockey, 1994) for which numerous students enrol part-time due to work and family commitments. The present study tested the assumption that certain phases of dissertation writing and stressors are perceived to be either stressful or not stressful and are thus evaluated positively or negatively. Although a stressor can be perceived in a positive or a negative way, it can also be simultaneously perceived as a challenge and a hindrance (Lazarus \& Folkman, 1984; Webster et al., 2011). Students' responses to the open-ended questions in this study demonstrated that stress can be evaluated as a challenge and a hindrance simultaneously.

The present study has certain limitations. The study was a cross-sectional survey and as a result, cause and effect relationships between variables could not be made. To understand causal relationships between variables, longitudinal or quasi-experimental designs should be considered for future research. Although the present study's hypothesis was derived from the transactional model of stress (moderation model) to assess the impact of the phases of dissertation writing on the relationship between stressor factors and the stress experienced, the method did not truly reflect the transactional model. A method using longitudinal data to test the transactional model (mediation model) accurately could be used to determine causal relationships. Also, only one item was used to determine stress experienced; thus, future research should use more than one item to measure the construct of stress.

Despite these limitations, the present study adds to the growing literature that shows that students are prone to experiencing high levels of stress when engaged with the dissertation writing process. The results of the present study show that there is a strong relationship between the stress experienced and dissertation writing and stressor factors. Various factors have been documented that affect postgraduate students' decisions to abandon their studies. Some of the psychological factors that have been documented are stress experienced and potential stressors, and these tend to 
influence students' decision to leave university (El-Ghoroury et al., 2012; Holahan, 1979; Martinsuo \& Turkulainen, 2011; Mechanic, 1962). However, the above-mentioned scholars focused mainly on doctoral students. Other researchers only focused on students from specific disciplines. El-Ghoroury et al. (2012) investigated stress and stressors among master's and doctoral students who were enrolled for psychology degrees, and Mechanic (1962) and Holahan (1979) investigated stress and coping mechanisms in doctoral students. Moreover, various literature focuses on overall stress and stressors among postgraduate students in the health sciences (Cahir \& Morris, 1991; El-Ghoroury et al., 2012; Holahan, 1979; Mechanic, 1962; Nelson, Dell'Oliver, Koch, \& Buckler, 2001). None of the literature discusses the relationship between stressors and the overall stress experienced when writing dissertations among students from various faculties.

\section{Conclusion}

There has been limited attention given to master's students writing dissertations. The results of this study show that there are implications for how master's programmes and university support services should be structured to improve students' academic well-being. The results also highlight that students evaluated the stress that they experienced in either a positive or a negative way. The stress that is experienced seems to be beneficial for those students who evaluate it positively. However, the stress that is experienced could also be destructive for those students who evaluate it negatively. This suggests that stress experienced is subject to students' perceptions. Students' perceptions of stress experienced can either motivate them to complete their dissertations or lead to procrastination.

\section{Funding}

The author(s) declared receipt of the following financial support for the research, authorship, and/or publication of this article: This reseach was supported by National Research Foundation S\&F - Scholarships and Fellowships Programme (Grant Unique Number: 844772NSF). While the scholarship has made this research possible, the work is entirely the author's responsibility.

\section{Notes}

1. Although the race categories are a function of apartheid policies, they still dominate post-apartheid discourse.

2. The dissertation phases in the present study were exploratory. Although the generally agreed upon lower limit for a Cronbach's alpha is .70, Hair, Black, Babin, Anderson, and Tatham (1998) highlight that the Cronbach's alpha can decrease in exploratory research.

3. Pseudonyms are used to refer to participants in the present study.

\section{ORCID iD}

Fortunate Tintswalo Silinda (iD https://orcid.org/0000-0001-9945-9839

\section{References}

Brand South Africa. (2017). South Africa's population. Retrieved from https://www.brandsouthafrica.com/ people-culture/people/south-africas-population

Cadman, K. (1997). Thesis writing for international students: A question of identity? English for Specific Purposes, 16, 3-14.

Cahir, N., \& Morris, R. D. (1991). The Psychology Student Stress Questionnaire. Journal of Clinical Psychology, 47, 414-417. 
Chaudron, D. (2006). Master of all you survey: How to use surveys to improve organizations, teams \& leaders. San Diego, CA: Organized Change Publications.

Creswell, J. W. (2013). Research design: Qualitative, quantitative, and mixed methods approaches. Thousand Oaks, CA: SAGE.

Delamont, S. (1992). Fieldwork in educational settings: Methods, pitfalls and perspectives. London, England: Falmer Press.

Department of Higher Education and Training. (2013). Statistics on post-school education and training in South Africa: 2011. Pretoria, South Africa: Government Printer.

D'Zurilla, T. J., \& Sheedy, C. F. (1991). Relation between social problem-solving ability and subsequent level of psychological stress in college students. Journal of Personality and Social Psychology, 61, 841-846.

El-Ghoroury, N. H., Galper, D. I., Sawaqdeh, A. B., \& Bufka, L. F. (2012). Stress, coping, and barriers to wellness among psychology graduate students. Training and Education in Professional Psychology, 6, 122-134. doi:10.1037/a0028768

Flett, G. L., Stainton, M., Hewitt, P. L., Sherry, S. B., \& Lay, C. (2012). Procrastination automatic thoughts as a personality construct: An analysis of the Procrastinatory Cognitions Inventory. Journal of RationalEmotive \& Cognitive-Behavior Therapy, 30, 223-236.

Folkman, S. (1997). Positive psychological states and coping with severe stress. Social Science \& Medicine, $45,1207-1221$.

Gardner, S. K. (2009). The development of doctoral students: Phases of challenge and support. ASHE Higher Education Report, 34(6), 1-126.

Gibbons, C. (2010). Stress, coping and burnout in nursing students. International Journal of Nursing Studies, $47,1299-1309$.

Golde, C. M. (2005). The role of the department and discipline in doctoral student attrition: Lessons from four departments. Journal of Higher Education, 76, 669-700.

Hair, J. F., Black, W. C., Babin, B. J., Anderson, R. E., \& Tatham, R. L. (1998). Multivariate data analysis (Vol. 5). Upper Saddle River, NJ: Prentice Hall.

Hayes, A. F., \& Preacher, K. J. (2014). Statistical mediation analysis with a multicategorical independent variable. British Journal of Mathematical and Statistical Psychology, 67, 451-470.

Herman, C. (2011). Obstacles to success - Doctoral student attrition in South Africa. Perspectives in Education, 29(3), 40-52.

Hockey, J. (1994). New Territory: Problems of adjusting to the first year of a social science PhD. Studies in Higher Education, 19, 177-190.

Holahan, C. K. (1979). Stress experienced by women doctoral students, need for support, and occupational sex typing: An interactional view. Sex Roles, 5, 425-436.

Jacobs, S. R., \& Dodd, D. (2003). Student burnout as a function of personality, social support, and workload. Journal of College Student Development, 44, 291-303.

Jiao, Q. G., DaRos-Voseles, D. A., Collins, K. M., \& Onwuegbuzie, A. J. (2011). Academic procrastination and the performance of graduate-level cooperative groups in research methods courses. Journal of the Scholarship of Teaching and Learning, 11, 119-138.

Klassen, R. M., \& Chiu, M. M. (2010). Effects on teachers' self-efficacy and job satisfaction: Teacher gender, years of experience, and job stress. Journal of Educational Psychology, 102, 741-756.

Lazarus, R. S. (1966). Psychological stress and the coping process. New York, NY: McGraw-Hill.

Lazarus, R. S., \& Folkman, S. (1984). Stress, appraisal, and coping. New York, NY: Springer.

LePine, J. A., LePine, M. A., \& Jackson, C. L. (2004). Challenge and hindrance stress: Relationships with exhaustion, motivation to learn, and learning performance. Journal of Applied Psychology, 89, 883-891.

Li, L. Y., \& Vandermensbrugghe, J. (2011). Supporting the thesis writing process of international research students through an ongoing writing group. Innovations in Education and Teaching International, 48, 195-205.

Lovitts, B. E. (2001). Leaving the ivory tower. Lanham, MD: Rowman \& Littlefield.

Martinez, E., Ordu, C., Della Sala, M. R., \& McFarlane, A. (2013). Striving to obtain a school-work-life balance: The full-time doctoral student. International Journal of Doctoral Studies, 8, 39-59. 
Martinsuo, M., \& Turkulainen, V. (2011). Personal commitment, support and progress in doctoral studies. Studies in Higher Education, 36, 103-120. doi:10.1080/03075070903469598

Maunganidze, L., Sodi, T., Mudhovozi, P., Mberi, E., \& Mutasa, J. (2010). Academic counselling for graduate research students with distance learning. Journal of Psychology in Africa, 20, 95-99.

Mechanic, D. (1962). Students under stress: A study of the social psychology of adaptation. Oxford, UK: The Free Press of Glencoe.

Mudhovozi, P. (2011). Analysis of perceived stress, coping resources and life satisfaction among students at a newly established institution of higher learning. South African Journal of Higher Education, 25, $510-522$.

Nelson, N. G., Dell'Oliver, C., Koch, C., \& Buckler, R. (2001). Stress, coping, and success among graduate students in clinical psychology. Psychological Reports, 88, 759-767.

Overall, N. C., Deane, K. L., \& Peterson, E. R. (2011). Promoting doctoral students' research self-efficacy: Combining academic guidance with autonomy support. Higher Education Research \& Development, 30, 791-805.

Paltridge, B. (2002). Thesis and dissertation writing: An examination of published advice and actual practice. English for Specific Purposes, 21, 125-143.

Pillay, A. L., \& Ngcobo, H. S. (2010). Sources of stress and support among rural-based first-year university students: An exploratory study. South African Journal of Psychology, 40, 234-240.

Porter, S. R., \& Umbach, P. D. (2006). Student survey response rates across institutions: Why do they vary? Research in Higher Education, 47, 229-247.

Samraj, B. (2008). A discourse analysis of master's theses across disciplines with a focus on introductions. Journal of English for Academic Purposes, 7, 55-67.

Shapiro, J. (1983). Family reactions and coping strategies in response to the physically ill or handicapped child: A review. Social Science \& Medicine, 17, 913-931.

Silinda, F. T., \& Brubacher, M. R. (2016). Distance learning postgraduate student stress while writing a dissertation or thesis. International Journal of E-Learning \& Distance Education, 31(1), 1-14.

Strauss, A., \& Corbin, J. (1998). Basics of qualitative research techniques. Thousand Oaks, CA: SAGE.

Taylor, M., \& Owusu-Banahene, N. (2010). Stress among part-time business students: A study in a Ghanaian university campus. IFE PsychologIA, 18, 112-129.

Wang, T., \& Li, L. Y. (2008). Understanding international postgraduate research students' challenges and pedagogical needs in thesis writing. International Journal of Pedagogies and Learning, 4(3), 88-96.

Webster, J. R., Beehr, T. A., \& Love, K. (2011). Extending the challenge-hindrance model of occupational stress: The role of appraisal. Journal of Vocational Behavior, 79, 505-516. 